University of Nebraska - Lincoln

DigitalCommons@University of Nebraska - Lincoln

\title{
Computational model for predicting nonlinear viscoelastic damage evolution in materials subjected to dynamic loading
}

\author{
Flavio V. Souza \\ University of Nebraska-Lincoln, flaviovs@gmail.com \\ Yong-Rak Kim \\ University of Nebraska-Lincoln, yong-rak.kim@unl.edu \\ George A. Gazonas \\ U.S. Army Research Laboratory, gazonas@arl.army.mil \\ David H. Allen \\ University of Nebraska-Lincoln, dallen3@unl.edu
}

Follow this and additional works at: https://digitalcommons.unl.edu/mechengfacpub

Part of the Mechanics of Materials Commons, Nanoscience and Nanotechnology Commons, Other Engineering Science and Materials Commons, and the Other Mechanical Engineering Commons

Souza, Flavio V.; Kim, Yong-Rak; Gazonas, George A.; and Allen, David H., "Computational model for predicting nonlinear viscoelastic damage evolution in materials subjected to dynamic loading" (2009). Mechanical \& Materials Engineering Faculty Publications. 100.

https://digitalcommons.unl.edu/mechengfacpub/100

This Article is brought to you for free and open access by the Mechanical \& Materials Engineering, Department of at DigitalCommons@University of Nebraska - Lincoln. It has been accepted for inclusion in Mechanical \& Materials Engineering Faculty Publications by an authorized administrator of DigitalCommons@University of Nebraska Lincoln. 


\title{
Computational model for predicting nonlinear viscoelastic damage evolution in materials subjected to dynamic loading
}

\author{
Flavio V. Souza ${ }^{\text {a }}$, Yong-Rak Kim ${ }^{\mathrm{b}}$, George A. Gazonas ${ }^{\mathrm{c}, *}$, David H. Allen ${ }^{\mathrm{a}}$ \\ a Department of Engineering Mechanics, University of Nebraska-Lincoln, 114 Othmer Hall, Lincoln, NE 68588, USA \\ ${ }^{\mathrm{b}}$ Department of Civil Engineering, University of Nebraska-Lincoln, W351 Nebraska Hall, Lincoln, NE 68588, USA \\ ${ }^{c}$ U.S. Army Research Laboratory, Weapons and Materials Research Directorate, Aberdeen Proving Ground, MD 21005, USA
}

\section{A R T I C L E I N F O}

\section{Article history:}

Received 24 November 2008

Received in revised form 13 December 2008

Accepted 31 December 2008

Available online 7 May 2009

\section{Keywords:}

B. Debonding

B. Fracture

C. Computational modelling

C. Cohesive zone model

\begin{abstract}
A B S T R A C T
Many inelastic solids accumulate numerous cracks before failure due to impact loading, thus rendering any exact solution of the IBVP untenable. It is therefore useful to construct computational models that can accurately predict the evolution of damage during actual impact/dynamic events in order to develop design tools for assessing performance characteristics. This paper presents a computational model for predicting the evolution of cracking in structures subjected to dynamic loading. Fracture is modeled via a nonlinear viscoelastic cohesive zone model. Two example problems are shown: one for model validation through comparison with a one-dimensional analytical solution for dynamic viscoelastic debonding, and the other demonstrates the applicability of the approach to model dynamic fracture propagation in the double cantilever beam test with a viscoelastic cohesive zone.
\end{abstract}

Published by Elsevier Ltd.

\section{Introduction}

Recently, considerable research has been focused on the subject of dynamic crack propagation in solid continua, both experimentally [1-3], and theoretically [4,5]. As is well known, in the case wherein the object is ductile, the application of the J-integral [6] may be erroneous due to path dependence in the energy released during crack growth. Indeed, while the Griffith criterion [7] may still apply to crack propagation, it is possible that the energy required for crack propagation may not even be a material constant, but is more likely a material property that is both rate and history dependent [8]. Thus, it is quite likely that new fracture models need to be developed in order to predict crack propagation in these complicated media.

While several models have been previously proposed for predicting fracture of viscoelastic media [8-12], few have proposed a methodology whereby the fracture toughness may be measured a priori. One model that has been proposed utilizes a micromechanical analysis to build a cohesive zone model $[13,14]$, thereby resulting in a cogent methodology for determining the fracture toughness of viscoelastic media $[15,16]$. The model by Allen and Searcy $[15,16]$ results in a set of constitutive equations for the plane ahead of the crack tip. Predictions of energy release rates during crack growth have been made with the model for the case of quasi-static crack propagation $[17,18]$.

\footnotetext{
* Corresponding author. Tel.: +1 410306 0863; fax: +1 4103060759 .

E-mail address: gazonas@arl.army.mil (G.A. Gazonas).
}

It should be pointed out that in recent years numerous cohesive zone models have been proposed in the open literature. For example, the plasticity type models $[19,20]$, while they do account for history dependence, are not rate dependent. The micromechanical model by Sha et al. [21], while they do proceed from a microscale sufficient to experimentally determine material parameters, are also not rate dependent. In addition, numerical algorithms have been developed for predicting crack propagation. However, they either do not contain a rate-dependent cohesive zone model $[22,23]$, or they do not contain a micromechanical description of the cohesive zone model [24]. Finally, while analytical models of crack growth have been developed for media with imbedded cohesive zones $[25,26]$, they are not generally useful for computational code verification because they consider only a single crack undergoing mode III crack propagation.

In the current study, the authors focus on the issue of dynamic crack propagation, such as that which occurs in armor subjected to projectile impact [27]. In applications such as this, it is often observed experimentally that multiple cracks grow and interact simultaneously. Obviously, the prediction of the response of these types of structural components is analytically untenable, so that numerical approximations are the most likely candidates for utilization. In this study, a nonlinear viscoelastic cohesive zone model is incorporated into an explicit finite element program that was developed for the eventual goal of predicting the propagation of multiple cracks in viscoelastic media under dynamic loading conditions. In order to validate the model, analytic solutions for some problems are compared to computationally generated solutions. 
Analytic results derived and presented elsewhere [28] for onedimensional elastic media with an elastic or viscoelastic cohesive zone are compared herein to predictions made with the computational model developed. The validated computational code is then used on the analysis of an elastic dynamic double cantilever beam test with an embedded viscoelastic cohesive zone model for the propagating crack in order to demonstrate the applicability of the approach to model more complex problems. The important aspects of multiple dynamic crack propagation in viscoelastic media that focus on the interplay between viscoelastic dissipation in the cohesive zone and the bulk structure, and dynamic insertion criteria for cohesive zones in viscoelastic media are relegated to future work.

\section{Model formulation}

An initial boundary value problem for a general body developing cracks due to impact loading is considered in this study. Fig. 1 shows a general body containing discrete cracks with cohesive zones.

The body has an interior volume $V$ and a boundary $\partial V$ that is composed of two parts: $\partial V_{e}$, which denotes the part of the external boundary; and $\partial V_{c}$, which denotes the internal boundary herein associated with cohesive zones. The state variables to be predicted by the model are the displacement vector $u_{i}\left(x_{k}, t\right)$, the stress tensor $\sigma_{i j}\left(x_{k}, t\right)$, and the strain tensor $\varepsilon_{i j}\left(x_{k}, t\right)$, where $x_{k}$ are the spatial coordinates and $t$ is time.

Considering body forces and inertial effects, the conservation of linear momentum (for small displacements) can be expressed by,

$\sigma_{j i, j}+\rho b_{i}=\rho \ddot{u}_{i}$ in volume $V$

where $\rho$ is the mass density per unit volume, $b_{i}$ is the specific body force vector, and $\ddot{u}_{i}$ is the acceleration of the material point.

Neglecting any body moments, the conservation of angular momentum implies that the stress tensor must be symmetric, i.e.,

$\sigma_{j i}=\sigma_{i j}$ in volume $V$ and on boundary $\partial V$

The linearized form of the strain-displacement relationship for small strains is given by,

$\varepsilon_{i j}=\frac{1}{2}\left(u_{i, j}+u_{j, i}\right) \quad$ in volume $V$

The linear elastic constitutive relationship can be expressed as,

$\sigma_{i j}\left(x_{k}, t\right)=C_{i j k l}^{E} \varepsilon_{k l}\left(x_{k}, t\right)$ in volume $V$

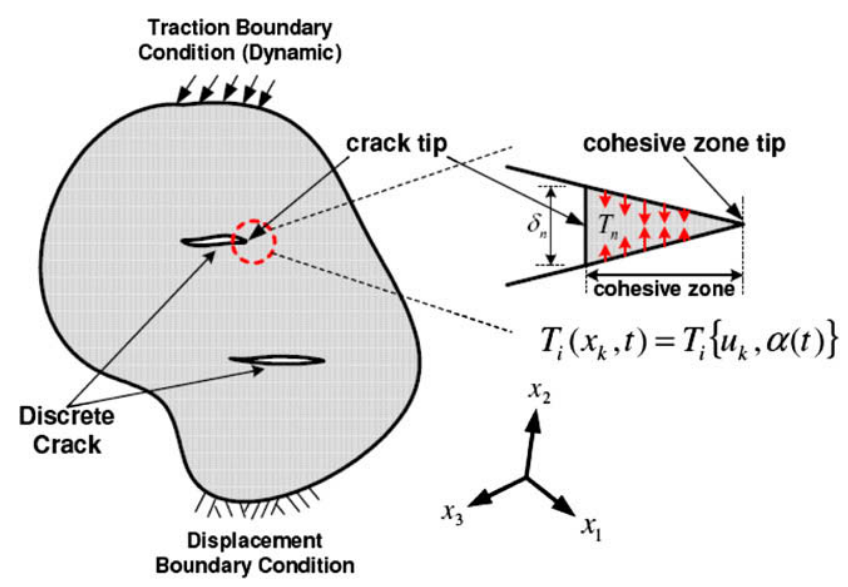

Fig. 1. A general body containing discrete cracks with cohesive zones. where $C_{i j k l}^{E}$ is the elastic modulus tensor, which is time independent, and $t$ is the time of interest.

If the material is linear viscoelastic, the constitutive equation may be represented by a convolution integral of the form,

$\sigma_{i j}\left(x_{k}, t\right)=\int_{0}^{t} C_{i j k l}^{V E}(t-\xi) \frac{\partial \varepsilon_{k l}\left(x_{k}, \xi\right)}{\partial \xi} d \xi \quad$ in volume $V$

where $C_{i j k l}^{V E}(t)$ is the stress relaxation modulus tensor, which is time dependent, and $\xi$ is an integration variable.

At the crack tips the cohesive zones have constitutive behavior that reflects the change in the cohesive zone material properties due to microscopic damage accumulation ahead of crack tips. This behavior may be expressed by the general traction-displacement relationship as follows,

$T_{i}\left(x_{k}, t\right)=T_{i}\left\{u_{k}, \alpha(t)\right\} \quad$ on $\partial V_{c}$

where $T_{i}$ is the cohesive zone traction vector, and $\alpha(t)$ is a function representing damage evolution characteristics.

The cohesive zone internal boundary, $\partial V_{c}$, is typically time varying. The \{\} implies history dependence for damaged zones which behave viscoelastically. The state of damage is characterized by the time-dependent damage evolution function, $\alpha(t)$.

The initial condition for all state variables are known and assumed to be zero, i.e.,

$\sigma_{i j}\left(x_{k}, t=0\right)=0$ in the volume $V$ and on the boundary $\partial V$

$\varepsilon_{i j}\left(x_{k}, t=0\right)=0$ in the volume $V$ and on the boundary $\partial V$

$u_{i}\left(x_{k}, t=0\right)=0$ in the volume $V$ and on the boundary $\partial V$

In addition, either tractions or displacements are specified along sub-sets of the boundary of the body. These general mixed boundary conditions are,

$T_{i}\left(x_{k}, t\right)=\widehat{T}_{i} \quad$ on $\quad \partial V_{e 1}$

$u_{i}\left(x_{k}, t\right)=\hat{u}_{i} \quad$ on $\quad \partial V_{e 2}$

where $\widehat{T}_{i}$ are the known boundary tractions, and $\hat{u}_{i}$ are the known boundary displacements.

The union of $\partial V_{e 1}$ and $\partial V_{e 2}$ becomes the total external boundary, $\partial V_{e}$, and $\partial V_{e 1}$ cannot overlap $\partial V_{e 2}$. With Eq. (1) through Eq. (9), the above initial boundary value problem is well-posed. A solution to this problem generally exists and depending on the specific nonlinearities introduced by crack propagation may be obtainable analytically and/or numerically.

A displacement-based finite element formulation is obtained from the weak form of the conservation of linear momentum, Eq. (1). The weak form at time $t$ using the principle of virtual work is given by,

$\int_{V}\left(\sigma_{i j, j}+\rho b_{i}-\rho \ddot{u}_{i}\right) \delta u_{i} d V=0$

where $\delta u_{i}$ represents an arbitrary virtual displacement field.

Integrating by parts and applying Gauss' divergence theorem and Cauchy's formula to Eq. (10) then gives,

$\int_{\partial V} T_{i} \delta u_{i} d S-\int_{V} \sigma_{i j} \delta u_{i, j} d V+\int_{V} \rho b_{i} \delta u_{i} d V-\int_{V} \rho \ddot{u}_{i} \delta u_{i} d V=0$

The first term in Eq. (11), representing the virtual work of tractions acting on the boundary, can then be separated into two parts: virtual work due to tractions acting on external $\left(\partial V_{e}\right)$ and internal $\left(\partial V_{c}\right)$ boundaries, respectively.

$\int_{\partial V_{e}} T_{i} \delta u_{i} d S_{e}-\int_{\partial V_{c}} T_{i} \delta u_{i} d S_{c}-\int_{V} \sigma_{i j} \delta u_{i, j} d V+\int_{V} \rho b_{i} \delta u_{i} d V$
$-\int_{V} \rho \ddot{u}_{i} \delta u_{i} d V=0$ 
Artificial viscosity is employed to mitigate high frequency ringing phenomena by augmenting the pressure in compressed elements, similar to the method in other explicit codes [29].

$$
\begin{aligned}
& \int_{\partial V_{e}} T_{i} \delta u_{i} d S_{e}-\int_{\partial V_{c}} T_{i} \delta u_{i} d S_{c}-\int_{V}\left(\sigma_{i j}+Q \delta_{i j}\right) \delta u_{i, j} d V \\
& \quad+\int_{V} \rho b_{i} \delta u_{i} d V-\int_{V} \rho \ddot{u}_{i} \delta u_{i} d V=0 \\
& Q=\rho v\left|\dot{\varepsilon}_{k k}\right|\left(Q_{1} v\left|\dot{\varepsilon}_{k k}\right|+Q_{2} C\right)
\end{aligned}
$$

where $Q$ is the artificial bulk viscosity, $\delta_{i j}$ is the Kronecker delta, $v$ is the volume of the element, $C$ is the speed of sound in the material, and $Q_{1}, Q_{2}$ are dimensionless constants.

By employing a spatial discretization scheme such as the finite element method, Eq. (13) can be finally written for explicit integration as,

$$
\begin{aligned}
& \ddot{u}_{i p} M_{p q} \delta u_{i q}=f_{i}^{E X T}-f_{i}^{I N T} \\
& M_{p q}=\rho v \delta_{p q} \\
& f_{i}^{E X T}=\int_{\partial V_{e}} T_{i} \delta u_{i} d S_{e}+\int_{V} \rho b_{i} \delta u_{i} d V \\
& f_{i}^{I N T}=\int_{V}\left(\sigma_{i j}+Q \delta_{i j}\right) \delta u_{i, j} d V+\int_{\partial V_{c}} T_{i} \delta u_{i} d S_{c}
\end{aligned}
$$

where $M_{p q}$ is the diagonalized mass matrix (lumped mass matrix), $f_{i}^{E X T}$ is the external force vector, and $f_{i}^{I N T}$ is the internal force vector.

The equations of motion are then algebraically solved by an explicit time integration scheme using a modified central difference method.

\section{Nonlinear viscoelastic cohesive zone model}

Modeling of fracture zones preceding crack tips is a complex subject. The fracture behavior can be modeled in many different ways, and one of the well-known approaches is to implement socalled "cohesive zones" as illustrated in Fig. 1 and in Eq. (6). Cohesive zone models are well-established tools in classical fracture mechanics developed to remove stress singularities ahead of crack tips. Many researchers $[13,14,19,20,30-37]$ have attempted to model the constitutive behavior for a cohesive zone in which the tractions are described in terms of the displacement differences across the cohesive zone.

The cohesive zone is typically modeled by employing interface elements to model the growth of new boundary surfaces both internal and external to the body through the incorporation of the microscale damage evolution law. A constitutive relation governing mechanical behavior of the cohesive zone is typically represented either by rate-independent models or by rate-dependent models. Needleman [19] and Tvergaard [20] presented rate-independent cohesive zone models based on continuum level depictions of inter-atomic forces and inter-atomic bond separation. However, rate-independent models often are not suitable for predicting rate-dependent crack growth in viscoelastic bodies. Recently, several studies $[25,38]$ have recognized the importance of including rate dependence in cohesive zone models.

Yoon and Allen [18] proposed a damage-dependent constitutive model for a rate-dependent cohesive zone in a thermo-viscoelastic solid. By using the Helmholtz free energy for a nonlinear viscoelastic material the cohesive zone constitutive equation can be constructed, with the resulting constitutive model containing an internal state variable representing microscale damage evolution within the cohesive zone. The nonlinear viscoelastic cohesive zone model $[15,18]$ can be expressed by,

$T_{i}(t)=\frac{u_{i}(t)}{\lambda(t) \cdot \delta_{i}} \cdot[1-\alpha(t)] \cdot\left[\int_{0}^{t} E^{c}(t-\xi) \frac{\partial \lambda(\xi)}{\partial \xi} d \xi\right] \quad$ on $\partial V_{c}$ where $i=n$ (mode I direction), $s$ (mode II direction), or $r$ (mode III direction), $T_{i}(t)$ is the cohesive zone area-averaged traction, $\lambda(t)$ is the dimensionless Euclidean norm of the cohesive zone displacements, $u_{i}(t)$ is cohesive zone displacement, $\delta_{i}$ is the cohesive zone material length parameter, $\alpha(t)$ is the damage evolution function, and $E^{c}(t)$ is the linear viscoelastic relaxation modulus of the cohesive zone.

The $\lambda(t)$ in the convolution integral is a normalized quantity coupling all three displacement components as follows,

$\lambda(t)=\sqrt{\left(\frac{u_{n}(t)}{\delta_{n}}\right)^{2}+\left(\frac{u_{s}(t)}{\delta_{s}}\right)^{2}+\left(\frac{u_{r}(t)}{\delta_{r}}\right)^{2}}$

The damage evolution is characterized by internal state variable, $\alpha(t)$. Note from Eq. (19) that when $\alpha(t)$ reaches the value of unity, the crack face traction decays to zero, thus resulting in crack extension. The damage evolution function can be directly determined by performing fracture tests as shown in several recent studies $[35,39,40]$. Alternatively, a phenomenological form of the damage evolution, Eqs. (21) and (22), which is a form of power relationship [15] as a function of the $\lambda(t)$ and internal state variable, $\alpha(t)$ can also be used, since it is appropriate for simulating rate-dependent damage growth due to cracking.

$\dot{\alpha}=A[\lambda(t)]^{m}, \quad$ when $\dot{\lambda}>0$ and $\alpha<1$

$\dot{\alpha}=0$, when $\dot{\lambda} \leqslant 0$ or $\alpha=1$

where $A$ and $m$ are microscale phenomenological material constants.

Rate-dependent viscoelastic damage evolution characteristics of the cohesive zone model used herein is demonstrated in Allen and Searcy [16] and is reproduced in Fig. 2 for purposes of illustration. Numerical simulations were performed for a single fibril in a cohesive zone subjected to three different rates, $U_{0}$, of ramp displacement. The damage accumulation, $\alpha$, parameter shown in the figure indicates a direct relationship between loading rate and damage evolution rate: as the rate of loading increases, so does the rate of damage. Also of note, slower rates of loading naturally induce a longer delay in damage initiation. Furthermore, a slower loading rate produces more compliant response due to the fact that the slow loading rate gives more time for the viscous mechanisms and microstructural damage in the cohesive zone to occur.

\section{Model validation}

In order to validate the computational model, a simple onedimensional finite elastic strip that is cohesively bonded to a rigid substrate, as illustrated in Fig. 3, has been studied and then analytic solutions of the problem were compared to computationally obtained predictions using the explicit finite element code. The good agreement between model predictions and analytic solutions verify that the developed computational technique is a useful tool to predict dynamic behavior including material viscoelasticity and rate-dependent fracture.

Analytical solutions were derived [28] for a variety of cohesive zone constitutive behaviors including linear elastic, viscous, and viscoelastic without debonding, and elastic cohesive zones with evolving internal damage. The computational model validation in this study was performed in two separate forms: validation of cohesive zone viscoelasticity by using the analytic solutions derived for the viscoelastic cohesive zone without debonding (Case 1) and the validation of cohesive zone fracture by comparing computational predictions to the analytic solutions developed for elastic cohesive zones with evolving internal damage (Case 2). These two subsequent steps were employed in this study, because there was no analytic solution currently available that could be compared to the 

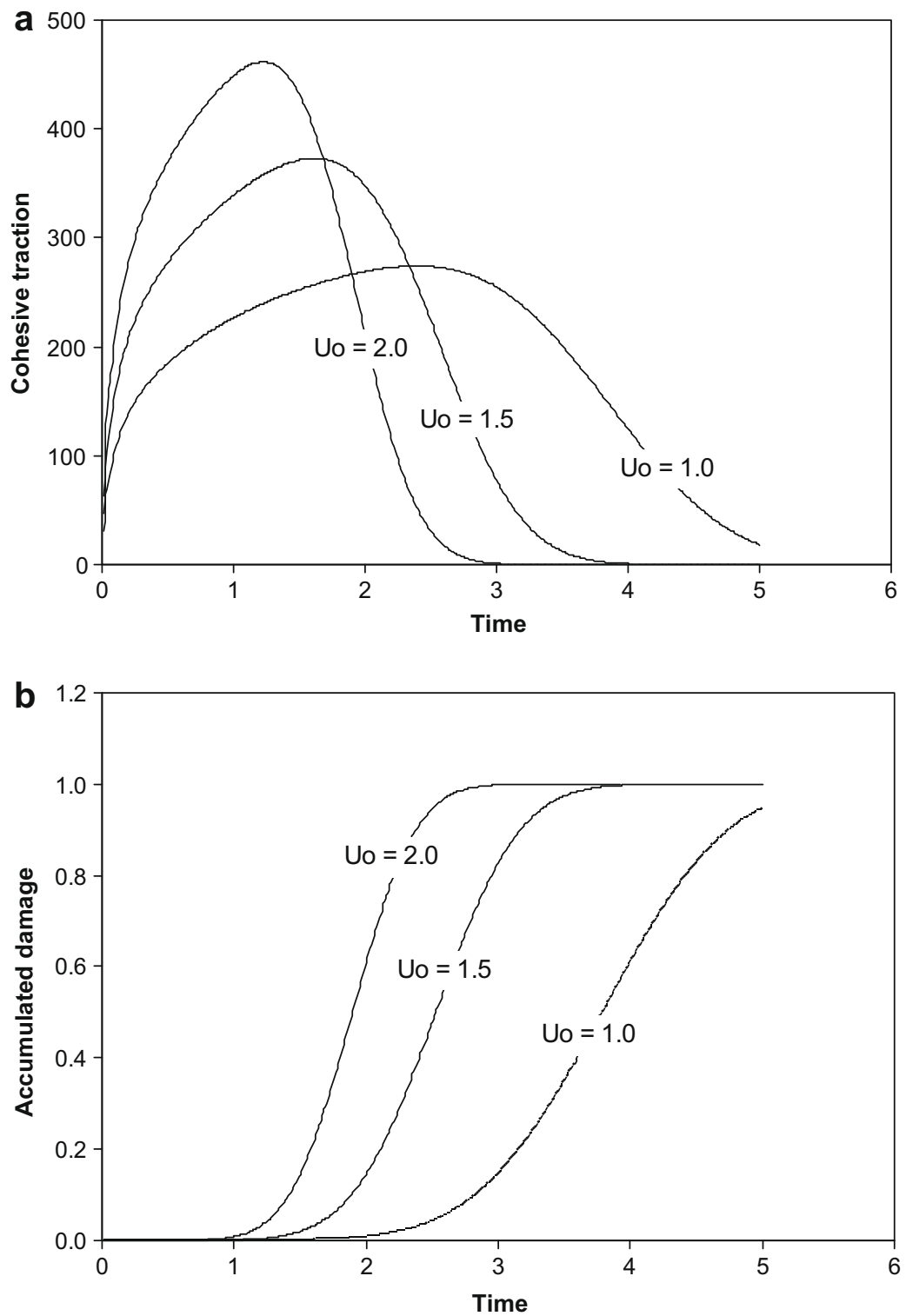

Fig. 2. Rate-dependent behavior of the viscoelastic cohesive zone model: (a) cohesive zone traction vs. loading time, and (b) accumulated damage vs. loading time.

nonlinear viscoelastic cohesive zone fracture by the computational model and the two separate validations in a combined form in this study can still check the model in terms of both material viscoelasticity and fracture failure of the cohesive zones.

\subsection{Case 1: viscoelastic cohesive zone without debonding}

Transient behavior of a finite strip with viscoelastic cohesive zones between the strip and the rigid substrate can be viewed as a one-dimensional wave equation using dimensionless variables, Eq. (23) and boundary conditions, Eqs. (24) and (25), as given,

$\frac{\partial^{2} u(x, t)}{\partial x^{2}}=\frac{\partial^{2} u(x, t)}{\partial t^{2}}$

$E \frac{\partial u(0, t)}{\partial x}=k u(0, t)+\eta \dot{u}(0, t)$

$E \frac{\partial u(l, t)}{\partial x}=p(t)=p_{o} H(t)$

where $E$ is the Young's modulus of the elastic finite strip, $k$ is the elastic stiffness of the cohesive zone, $\eta$ is the viscosity of the cohesive zone, $l$ is the length of the strip, $p_{o}$ is the constant tensile pres- sure applied on right-end boundary of the strip, and $H(t)$ is the Heaviside step function.

Following the notation found in Gazonas and Allen [28], analytical solutions to this boundary value problem in terms of the dimensionless D'Alembert solution for displacements and stresses in the finite strip are given,

$u(x, t)=F_{1}(t+x)+F_{2}(t-x)$

$\sigma(x, t)=E\left[F_{1}^{\prime}(t+x)-F_{2}^{\prime}(t-x)\right]$

$F_{1}(t)=\frac{p_{0}}{E} \sum_{n=0}^{\infty} L^{-1}\left\{\frac{1}{S^{2}}\left(\frac{1-a_{1}-a_{2} / S}{1+a_{1}+a_{2} / S}\right)^{n}\right\} H(t-2 n-1)$

$F_{2}(t)=\frac{p_{o}}{E} \sum_{n=0}^{\infty} L^{-1}\left\{\frac{1}{S^{2}}\left(\frac{1-a_{1}-a_{2} / S}{1+a_{1}+a_{2} / S}\right)^{n+1}\right\} H(t-2 n-1)$

$a_{1}=\frac{\eta t}{E}$

$a_{2}=\frac{l k}{E}$

where $L^{-1}$ is the inverse Laplace transform operator, $S$ is the Laplace transform variable, and primed quantities in Eq. (27) refer to spatial derivatives, $d / d x$. 


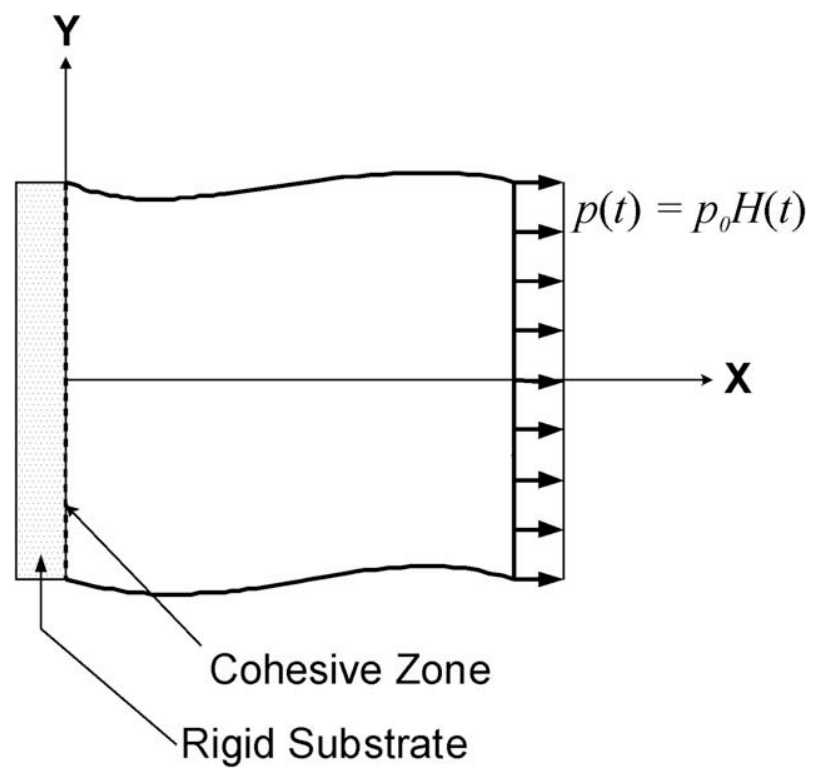

Fig. 3. A finite elastic strip subjected to dynamic tractions.

The dimensionless analytic solution for the stress at the center of the elastic strip with a viscoelastic cohesive zone, and subjected to a tensile Heaviside step loading is illustrated in Fig. 4 which compares well with computational predictions. Good agreement between the two results suggests that the finite element code has been developed appropriately in terms of material viscoelasticity of the cohesive zones. Furthermore, it is obvious that stresses are attenuated with time due to relaxation resulting from viscoelastic energy dissipation. Table 1 presents inputs including material properties, loading conditions, and geometry of the strip for each case used in this study.

\subsection{Case 2: cohesive zone with growing damage}

The computational model can be further validated by considering a general case where the viscoelastic cohesive zones are degraded and eventually resulting in decohesion due to rate- dependent damage evolution. In this case the boundary conditions are as follows,

$E \frac{\partial u(0, t)}{\partial x}=[1-\alpha(0, t)] \cdot\left[\frac{1}{\delta_{n}} \int_{0}^{t} E^{c}(t-\xi) \frac{\partial u(0, \xi)}{\partial \xi} d \xi\right]$

$E \frac{\partial u(l, t)}{\partial x}=p(t)=p_{o} H(t)$

The damage evolution function, $\alpha(t)$ has been previously defined and can be written as,

$\dot{\alpha}=A\left[\frac{u(0, t)}{\delta_{n}}\right]^{m}$

It can be noted that Eqs. (32) and (34) are reduced forms of Eqs. (19) and (21), respectively, from three-dimensional to one-dimensional case.

Note from Eq. (32) above that when $\alpha$ attains its maximum value of unity, the traction at the left end of the strip will become null, thus resulting in rigid body motion of the strip in the direction of the externally applied loading on the other boundary. Due to the nonlinearity in this problem, analytic solutions have been obtained only for a special case with the following conditions on the left boundary of the strip,

$\alpha(0, t)=\left\{\begin{array}{ll}0 & t<t_{f} \\ 1 & t \geqslant t_{f}\end{array}\right\}$

It is to be noted that Eq. (35) represents a special case of Eq. (34) that physically represents instantaneous crack growth at time $t=t_{f}$. This solution represents a limiting case that is nevertheless useful for validating the computational model. In order to obtain an analytic solution to the problem, the following boundary conditions are posed,

$E \frac{\partial u(0, t)}{\partial x}=k u(0, t) H\left(t-t_{f}\right)$

$E \frac{\partial u(l, t)}{\partial x}=p(t)=0$

The dimensionless displacements and stresses for this problem are

$u(x, t)=F_{1}(t+x)+F_{2}(t-x)$

$\sigma(x, t)=E\left[F_{1}^{\prime}(t+x)-F_{2}^{\prime}(t-x)\right]$

where $u(0, t)$ is the boundary displacement for the elastic cohesive zone problem without failure [28], and

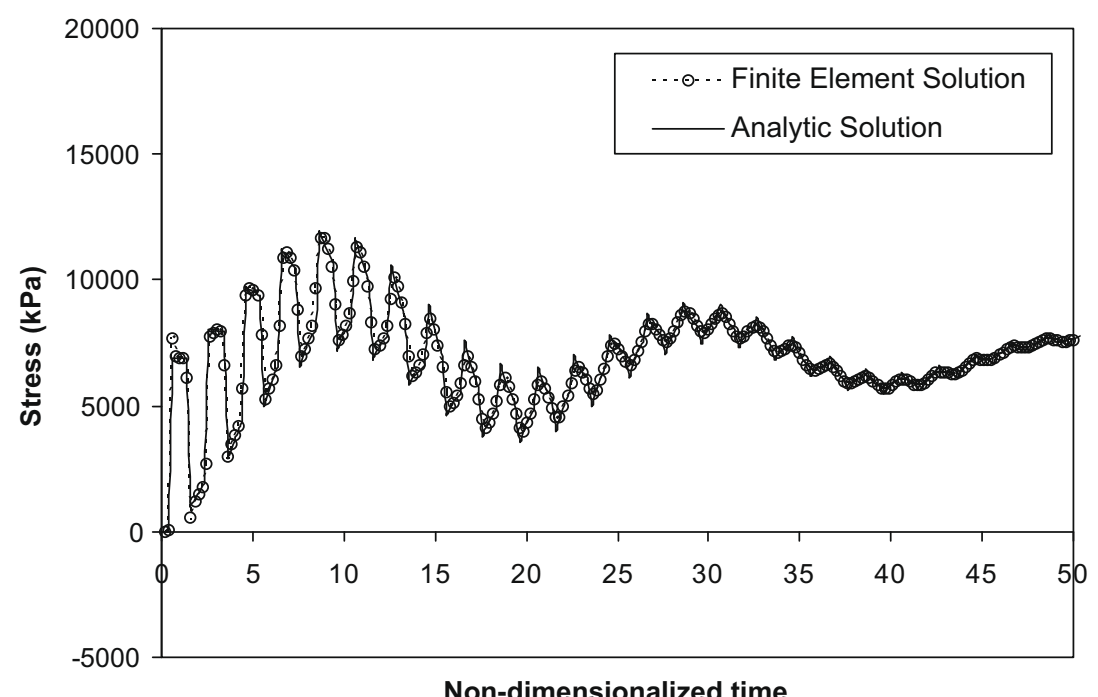

Fig. 4. Analytic solution vs. finite element solution at the center of the elastic strip with a viscoelastic cohesive zone (Case 1). 
Table 1

Inputs used for model validation.

\begin{tabular}{lll}
\hline Input & Case 1 & Case 2 \\
\hline Elastic strip & & \\
$E(\mathrm{kPa})$ & $2.07 \times 10^{8}$ & $2.07 \times 10^{8}$ \\
$\rho\left(\mathrm{kg}_{\mathrm{f}} \mathrm{s}^{2} / \mathrm{m}^{4}\right)$ & $7.99 \times 10^{2}$ & $7.99 \times 10^{2}$ \\
$l(\mathrm{~m})$ & $7.62 \times 10^{-1}$ & $7.62 \times 10^{-1}$ \\
Cohesive zone & & \\
$k\left(\mathrm{~kg}_{\mathrm{f}} / \mathrm{m}\right)$ & $1.79 \times 10^{6}$ & $1.79 \times 10^{6}$ \\
$\eta\left(\mathrm{kg}_{\mathrm{f}} \mathrm{s} / \mathrm{m}^{2}\right)$ & $7.03 \times 10^{3}$ & - \\
Load & & $6.895 \times 10^{3}$ \\
$P_{o}(\mathrm{kPa})$ & $6.895 \times 10^{3}$ & \\
\hline
\end{tabular}

$F_{1}(t)=-a \sum_{n=0}^{\infty} H\left(t-2 n-2-t_{f}\right) \int_{t_{f}}^{t-2 n-2} u(0, \xi) d \xi$

$F_{2}(t)=-a \sum_{n=0}^{\infty} H\left(t-2 n-t_{f}\right) \int_{t_{f}}^{t-2 n} u(0, \xi) d \xi$

$a=\frac{l k}{E}$

The solution to the problem with the cohesive zone failure is illustrated in Fig. 5 which compares favorably with the explicit finite element solution. After failure, $t \geqslant t_{f}$, the stress wave traverses the "failed" finite elastic strip and remains unaltered in form for all time. The solutions derived in this section are general in form and can predict the transient failure behavior of finite elastic strips with arbitrary values of the post-failure stiffness characterized by the material constant $a$, shown in Eq. (42).

\section{Application of the model}

In order to demonstrate the applicability and efficacy of this computational modeling approach, a double cantilever beam (DCB) specimen with damage-induced viscoelastic cohesive zones is subjected to dynamic loading by either displacement-controlled or force-controlled mode. The material properties of the specimen were arbitrarily selected and are given in Table 2 . The finite element mesh used herein is shown in Fig. 6 where the cohesive zone interface elements are inserted along the middle of the specimen (from $0.02-\mathrm{m}$ to $0.10-\mathrm{m}$ ). Note that a $0.02-\mathrm{m}$ long pre-crack is embedded along the centerline of the double cantilever beam specimen. The viscoelastic constitution of the cohesive zone is repre- sented by a Prony series stress relaxation modulus based on the generalized Maxwell model [11].

For the force-controlled loading mode, a dynamic, monotonically increasing vertical force $F= \pm 1.5 \times 10^{3} t H(t)$ (in Newton) was applied to the upper and lower tips of each cantilever beam to induce opening mode failure. Similarly, for the displacementcontrolled loading condition, a monotonically increasing vertical displacement $u= \pm 5.0 \times 10^{-2} t H(t)$ (in meter) was applied to each cantilever beam. Simulations were terminated when all of viscoelastic cohesive zones were failed resulting in complete separation of the double cantilever beam into two pieces. Elastic cohesive zone simulations were also performed by specifying all relaxation times (i.e., $\eta_{i} / E_{i}$ ) in the Prony series to be infinite. It is important to note that the "elastic" cohesive zone model, as described herein, is history-dependent in order to directly compare the effects of rate dependence due to material viscoelasticity alone without damage evolution effects. In order to simulate history-independent cohesive behavior, one might use models such as those described in Tvergaard [43], Camacho and Ortiz [41], or Zhou and Molinari [34].

Fig. 7 shows the applied force-tip displacement curve for elastic and for viscoelastic cohesive zones when the specimen is under force-controlled mode. As can be clearly seen from the figure, the viscoelastic cohesive zone produces a more compliant response than the elastic cohesive zone; the elastic and viscoelastic responses become indistinguishable at the highest loading rate of $1500 \mathrm{~N} / \mathrm{s}$ for the particular choice of material properties.

Fig. 8 presents the evolution of the normal traction at the first cohesive zone interface element $(0.02 \mathrm{~m})$, where one can see the gradual degradation of the cohesive zone for both force-controlled and displacement-controlled mode. It can also be observed from Fig. 8 that more energy is dissipated from the viscoelastic cohesive zones, as expected.

The damage evolution at different locations along the specimen center line for both loading conditions is shown in Fig. 9. From the figure, it can be seen that the shape of damage evolution varies with location and the loading mode.

Fig. 10 presents the time at which the crack has propagated (i.e., $\alpha(t)=1.0)$ as a function of location along the center line of the specimen where damage is induced from the viscoelastic cohesive zone. One interesting result is that for the material properties used, a single major crack is typically observed to propagate the length of the DCB specimen; for some simulations, however, cohesive elements close to the right end of the specimen (i.e., $x=0.10 \mathrm{~m}$ )

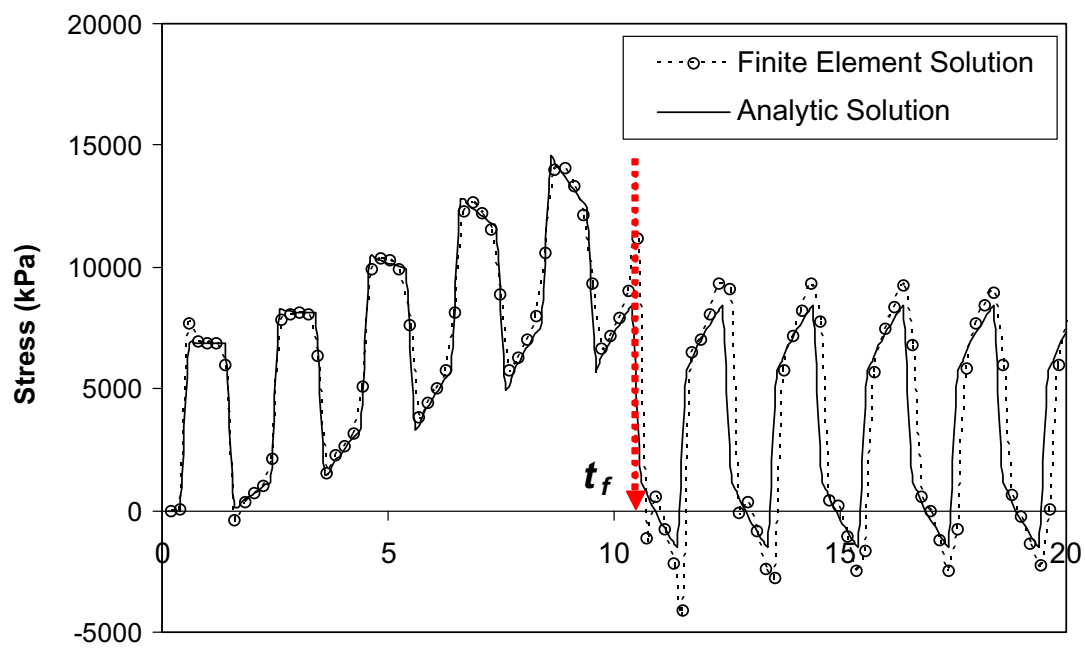

Non-dimensionalized time

Fig. 5. Analytic solution vs. finite element solution at the center of the elastic strip with an elastic cohesive zone that is subjected to failure (Case 2). 
Table 2

Material properties used for the double cantilever beam simulations.

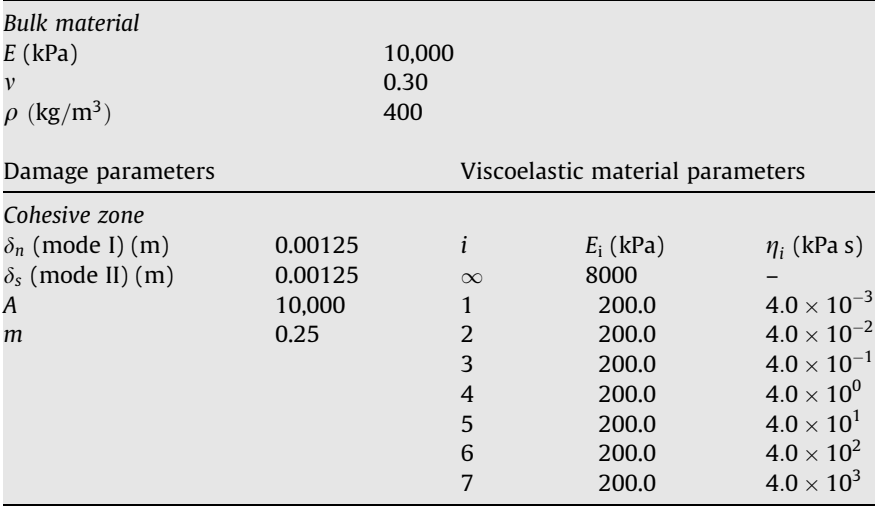

sometimes fail prior to the time that the major crack reaches that position, indicating that a secondary crack has been initiated, due to stress waves that have reached the right-end boundary. This behavior is more pronounced for the force-controlled case. It is important to note that the numerical approach used in the current study allows damage growth for any stress level greater than zero (note that Eq. (19) has no parameter defining the stress level at which damage is allowed to initiate), which allowed the initiation of the secondary crack from the right-end boundary as stress waves have reached that position. A more realistic approach can be developed by adding to the model a parameter that defines the stress level at which damage is allowed to initiate and use a constraint condition such as the Lagrange multiplier method to preclude cohesive zone opening at lower stress levels. Another approach that could be used to avoid damage initiation at any stress level is the use of an extrinsic cohesive zone model and the algorithm to automatically insert cohesive zone elements into the mesh [34,41].

One can also note from Fig. 10 that initially the crack propagates at an approximately constant velocity and at the same velocity for both force-controlled and displacement-controlled cases, which is also in good agreement with experimental and analytical results [42].

In an attempt to more closely investigate the energy dissipation behavior associated with cohesive zone damage in the specimen, each source of energy (strain energy, kinetic energy, and cohesive zone dissipated energy) from the displacement-controlled test was computed and is presented in Fig. 11. The cohesive zone dissipated energy is equivalent to the work done by the cohesive zone traction while damage is evolving and is calculated as follows,

$U_{C Z}(t)=\int_{0}^{t} \int_{S_{C Z}} k(t) T_{i}(t) \dot{u}_{i}(t) d S d t$

where $U_{C Z}(t)$ is the dissipated energy on the cohesive zones at time $t, S_{C Z}$ is the area of the cohesive zone interface elements, and $k$ is a constant used to prevent $U_{C Z}(t)$ from growing while damage is not evolving and is defined as,

$k(t)= \begin{cases}1, & \text { when } \dot{\lambda}>0 \\ 0, & \text { otherwise }\end{cases}$

Fig. 11 demonstrates that even though the applied external work always increases, at certain times the strain energy stored in the specimen decreases due to crack propagation, and approaches zero as

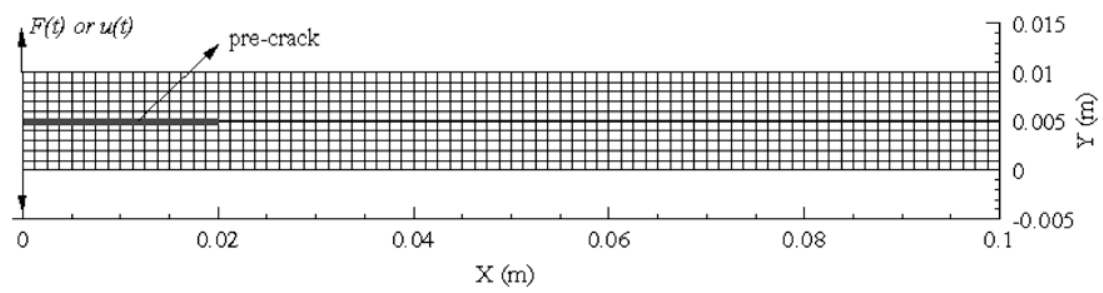

Fig. 6. Finite element mesh representing double cantilever beam geometry.

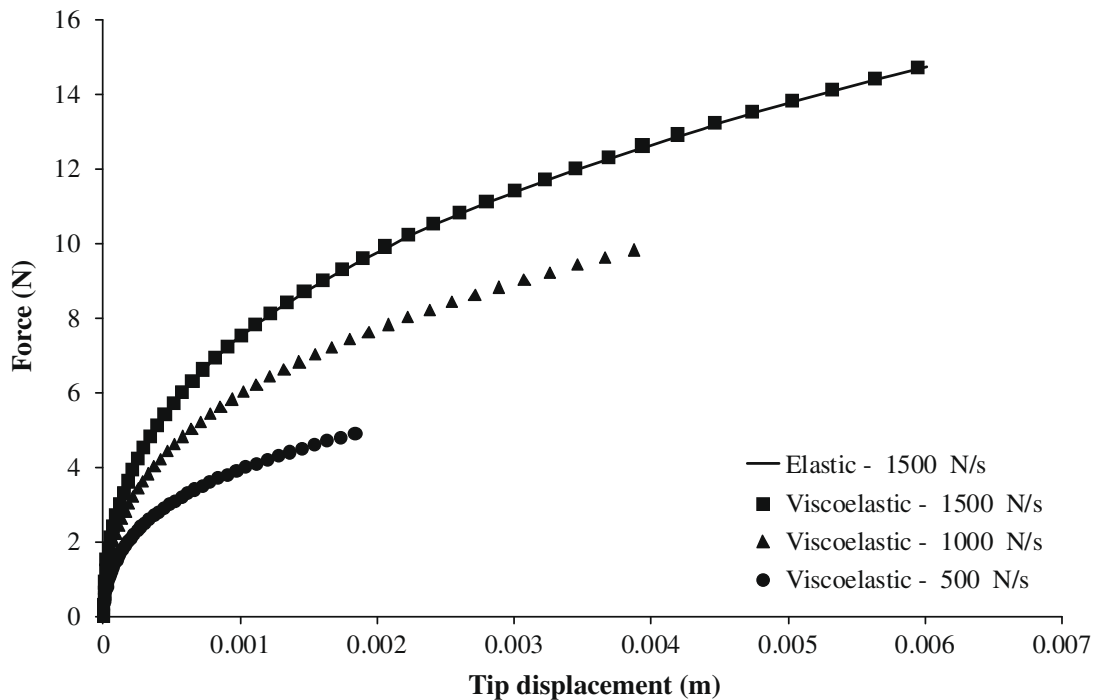

Fig. 7. Applied force-tip displacement curve for elastic and viscoelastic cohesive zone when the DCB specimen is subjected to force-controlled dynamic loading 


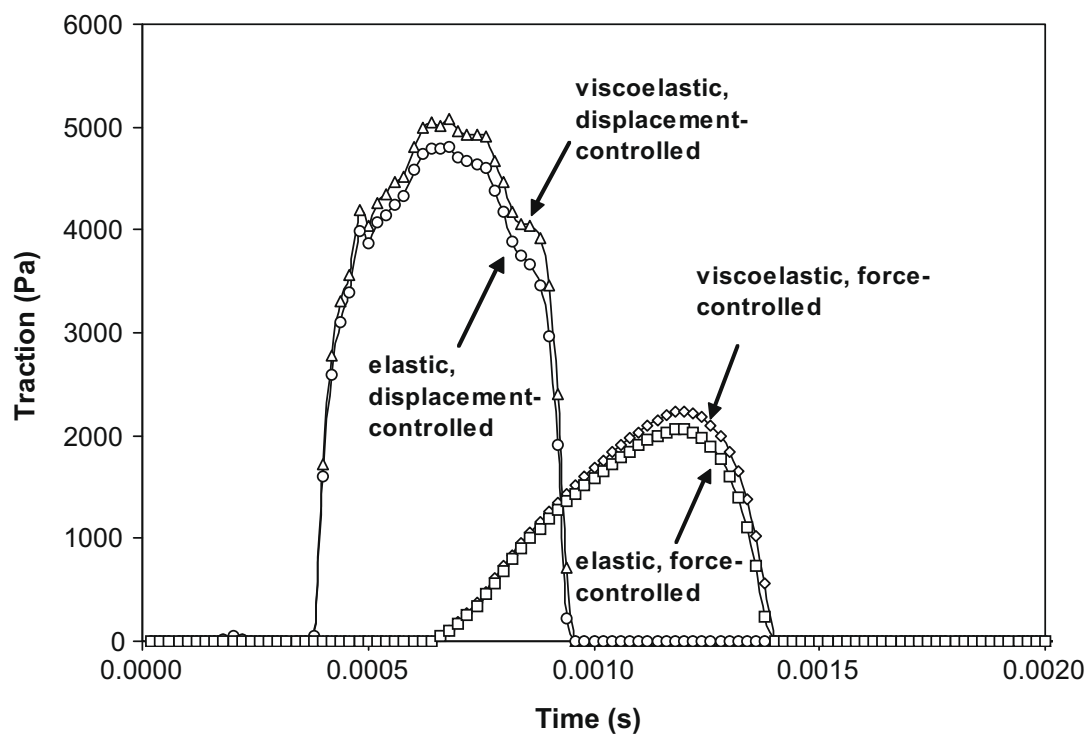

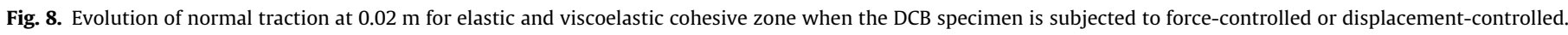
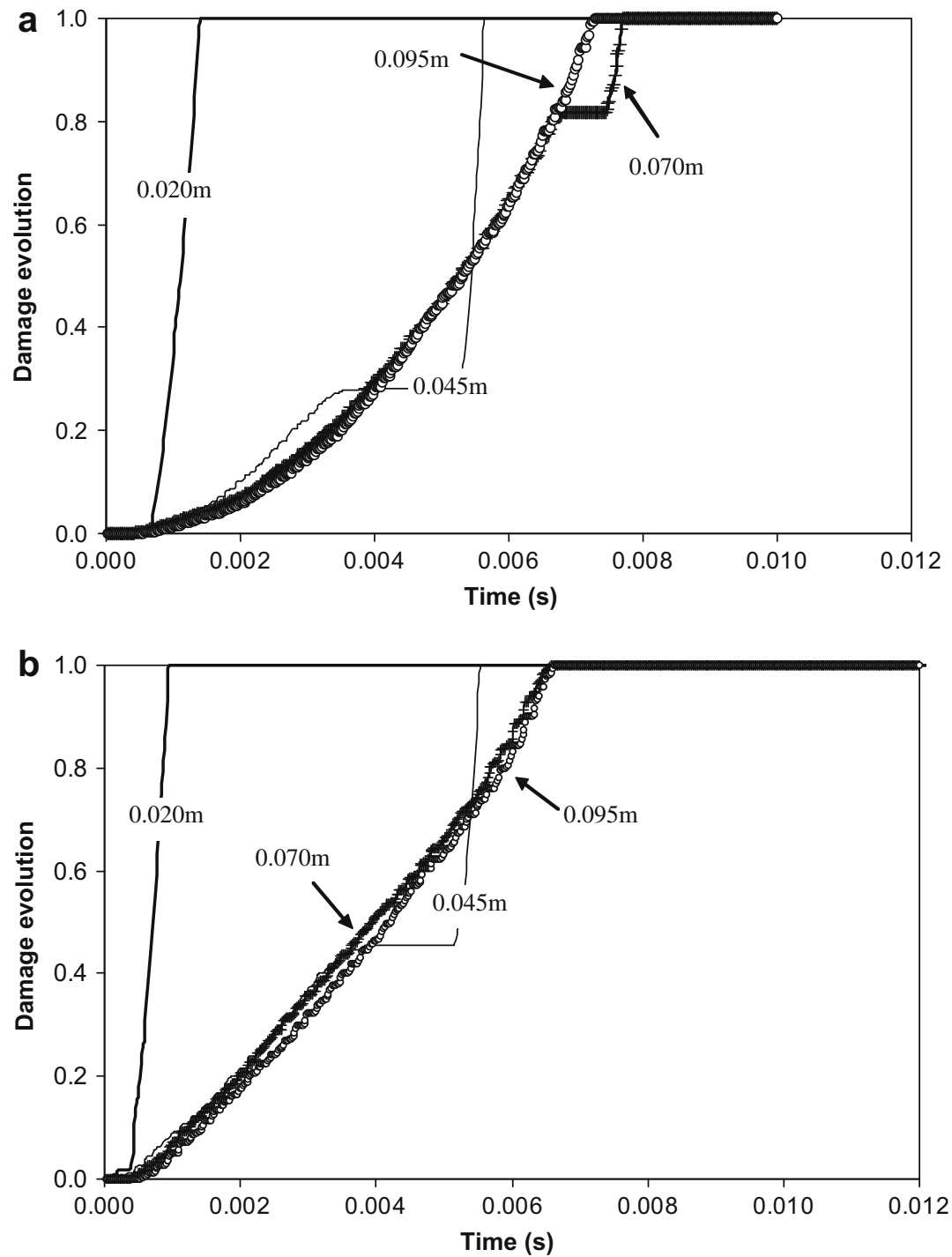

Fig. 9. Damage evolution at selected positions along the DCB center line for (a) force-controlled case and (b) displacement-controlled case. 


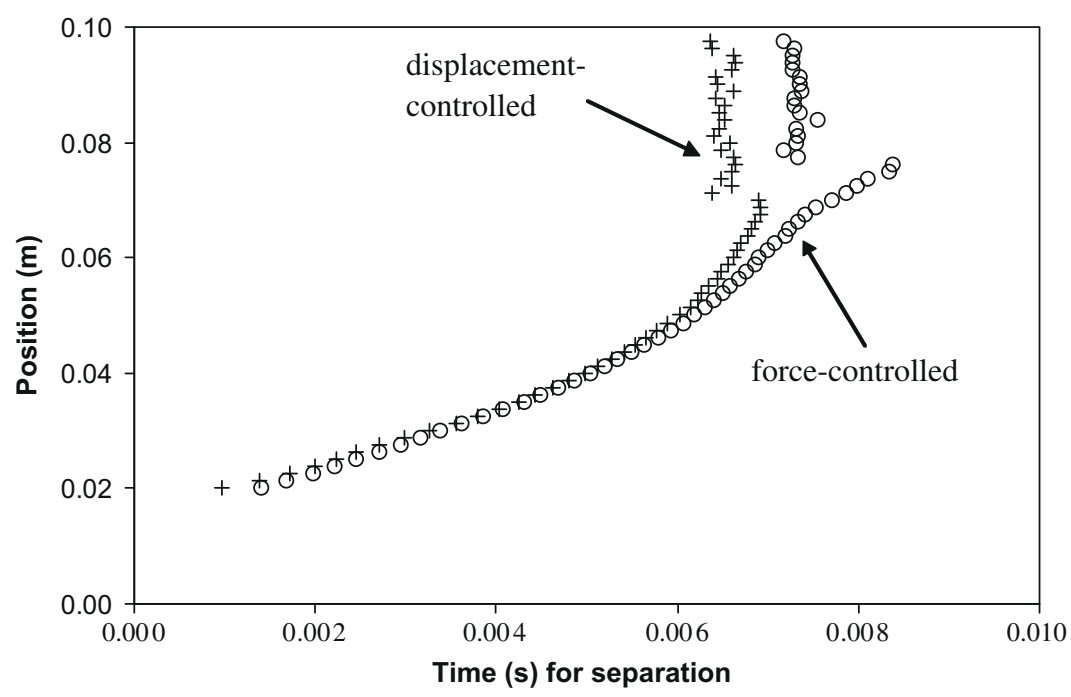

Fig. 10. Time at which $\alpha(t)=1.0$ as a function of location in a DCB specimen.

the crack length approaches the specimen size. It can also be seen that the viscoelastic cohesive zone dissipates more energy than the elastic cohesive zone.

Fig. 12 plots the level of damage developed along the viscoelastic cohesive zone at selected times for both loading cases. As expected, the damage level increases as loading continues, and cohesive zone elements closer to the crack tip experience a more accelerated damage build-up resulting in crack propagation. However, as previously noted, the cohesive zone elements closer to the right end of the specimen $(x=0.10 \mathrm{~m})$ fail somewhat earlier than the time it takes for the major crack to reach that position, due to the reasons previously discussed, which leads to two cracks: a primary crack propagating from the left to the right and a secondary crack propagating from the right end to the left. Another interesting fact to be noted from the figure is that damage curves along the cohesive zones exhibit fluctuation due to stress wave effects.

The cohesive zone normal traction vs. time (at $0.02 \mathrm{~m}$ ) response is shown in Fig. 13 which demonstrates that at low rates of loading stresses are lower than at higher rates of loading due to viscoelastic dissipation in the cohesive zone.
The ratios of kinetic energy, strain energy and cohesive zone dissipated energy to the total applied external work for three different loading (tip displacement) rates are plotted in Fig. 14a, b, and c, respectively. Fig. 14c illustrates that the lowest rate dissipates more energy through the cohesive zone, and allows more strain energy to be stored in the bulk of the elastic strip, as expected. Also note from Fig. 14(a-c) that in the initial stage of loading, the energy partition is the same for all loading rates, but as the cohesive zones develop and the crack propagates, the rate-dependent viscoelastic behavior is more pronounced.

\section{Concluding remarks}

A finite element method-based computational model has been presented herein for analysis/design of structures subjected to dynamic/impact loading and corresponding damage growth due to cracking. A nonlinear viscoelastic cohesive zone fracture model has been implemented into the explicit finite element formulation to represent time- and rate-dependent crack growth.

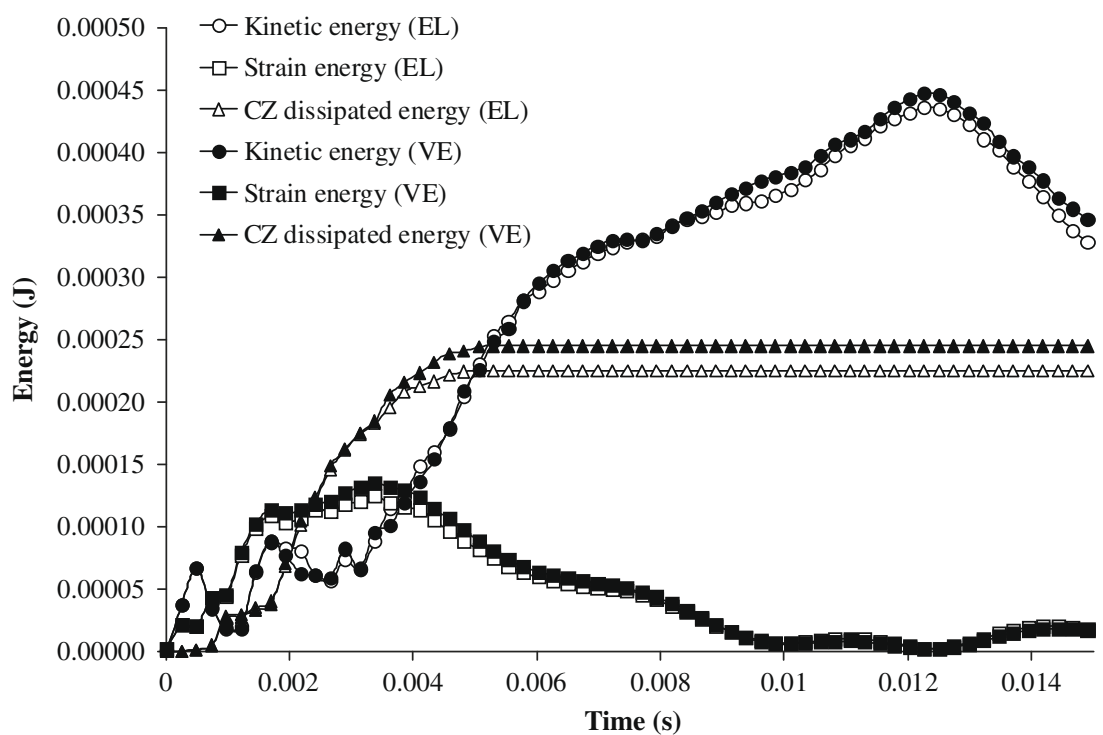

Fig. 11. Computed history of energy composition in a DCB from displacement-controlled tests: VE, viscoelastic; EL, elastic. 

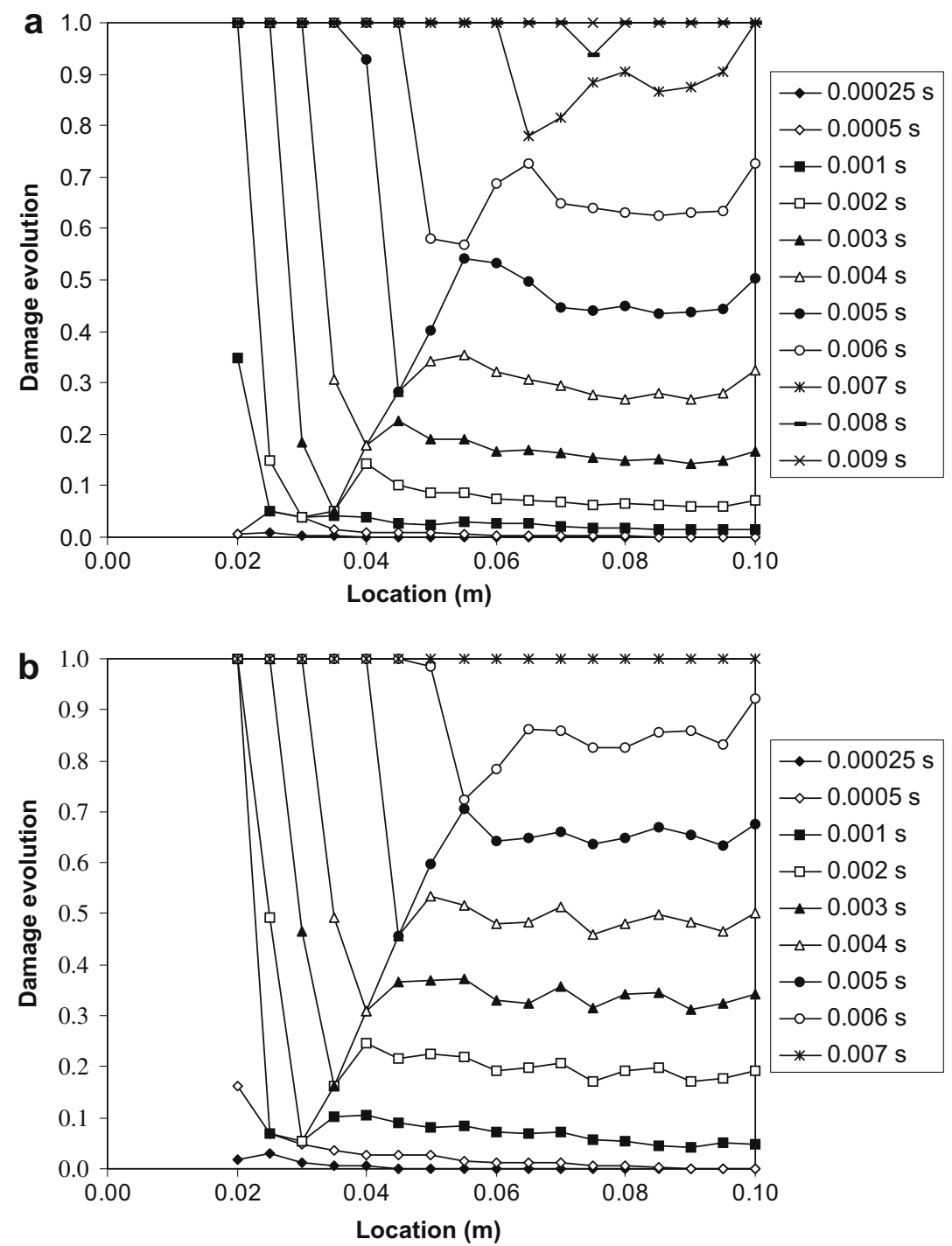

Fig. 12. Level of damage developed in a DCB at selected times along the viscoelastic cohesive zone for (a) force-controlled case; (b) displacement-controlled case.

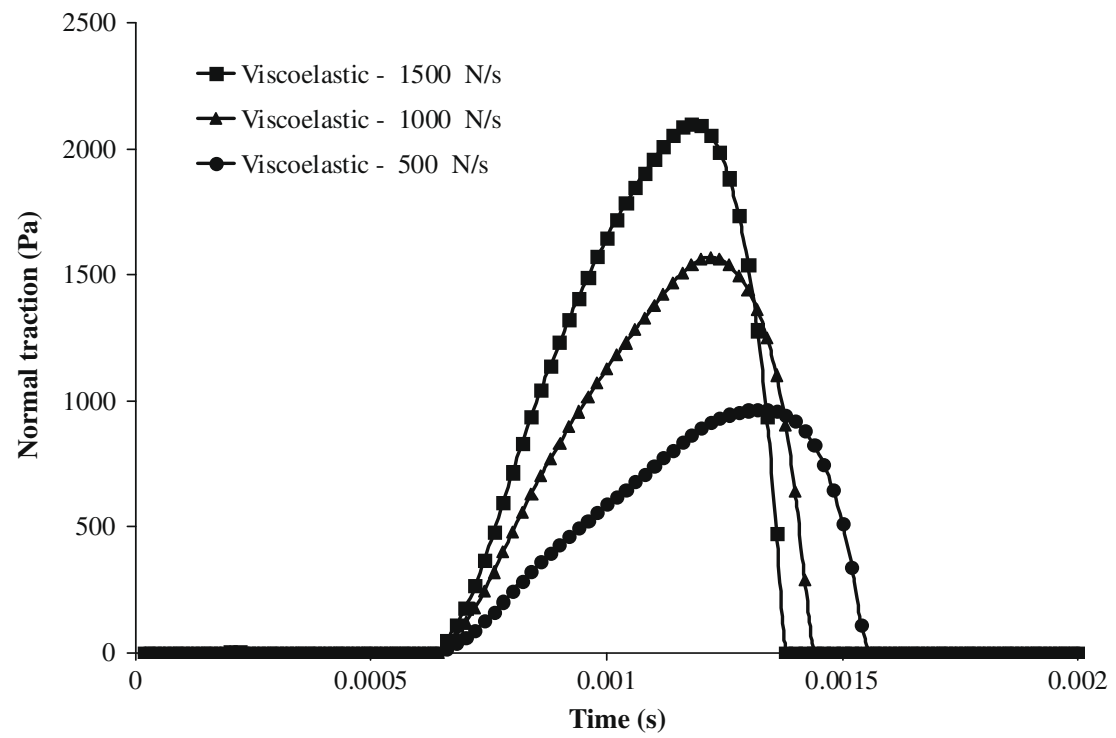

Fig. 13. Effect of loading rate (force control) on the traction response in a DCB at $0.02 \mathrm{~m}$. 

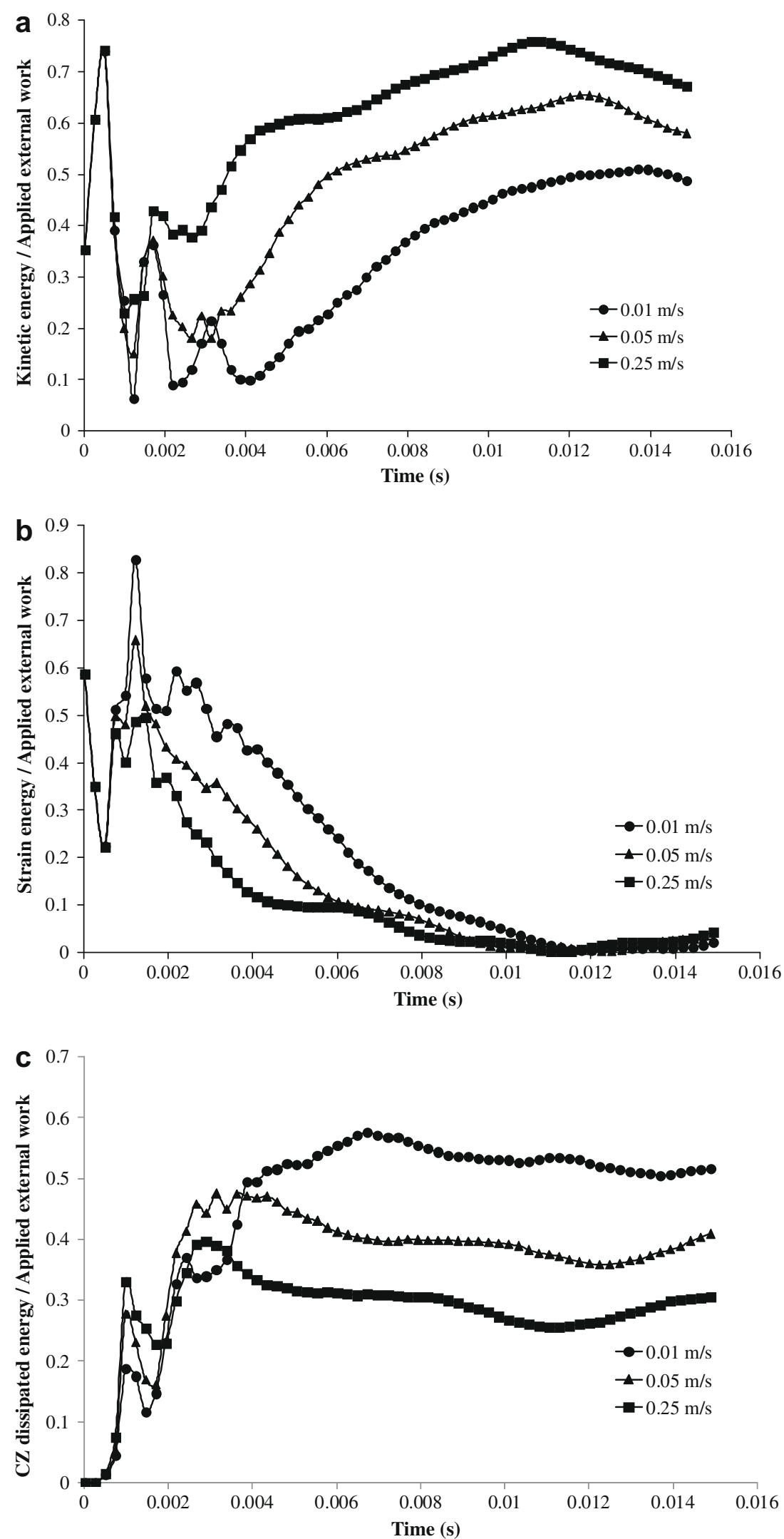

Fig. 14. Loading rate dependence on energy partitioning in a DCB with a viscoelastic cohesive zone (a) kinetic energy; (b) strain energy, and; (c) CZ dissipated energy.

Computational results obtained using the model have been successfully validated by comparing model predictions with analytical solutions for a simple one-dimensional finite strip that is cohesively bonded to a rigid substrate. Results obtained from computa- tional simulations have essentially, within its accuracy, reproduced the analytical solutions, mathematically derived. Also, results obtained for a dynamic double cantilever beam (force- and displacement-controlled) with a growing crack appear to be qualitatively 
correct, even though the authors have not been able to compare these with experimental data. The proposed technique may be useful for modeling various types of materials that exhibit viscoelastic behavior and complex nonlinear damage evolution characteristics due to dynamic/impact loading. The approach herein presented may be also utilized within a multiscale computational model in order to provide a predictive design tool for various structures subjected to dynamic/impact loading. Further validation of the model based on comparisons to experimental results is currently underway by the authors.

\section{Acknowledgements}

The authors acknowledge the support provided by the U.S. Army Research Office under Cooperative Agreement No. W911NF-04-2-0011. The first author also acknowledges the financial support from CNPq, Conselho Nacional de Desenvolvimento Cientifico e Tecnologico - Brazil.

\section{References}

[1] Lambros J, Rosakis AJ. Dynamic decohesion of bimaterials: experimental observations and failure criteria. Int J Solids Struct 1995;32:2677-702.

[2] Ravi-Chandar K, Yang B. On the role of microcracks in the dynamic fracture of brittle materials. J Mech Phys Solids 1997;45:535-63.

[3] Venkert A, Guduru PR, Ravichandran G. An investigation of dynamic failure in 2.3Ni-1.3Cr-0.17Steel. Met Mat Trans A 2000;31A:1147-54.

[4] Pandolfi A, Guduru PR, Ortiz M, Rosakis AJ. Three dimensional cohesiveelement analysis and experiments of dynamic fracture in C300 steel. Int J Solids Struct 2000;37(27):3733-60.

[5] Samudrala O, Huang Y, Rosakis AJ. Subsonic and intersonic mode II crack propagation with a rate-dependent cohesive zone. J Mech Phys Solids 2002;50:1231-68.

[6] Rice JR. A path independent integral and the approximate analysis of strain concentration by notches and cracks. J Appl Mech 1968;35:379-86.

[7] Griffith AA. The phenomena of rupture and flow of solids. Philos Trans R Soc Lond 1920;A221:163-97.

[8] Schapery RA. Correspondence principles and a generalized $J$ integral for large deformation and fracture analysis of viscoelastic media. Int J Fracture 1984:25:195-223.

[9] Knauss WG, Dietmann H. Crack propagation under variable load histories in linearly viscoelastic solids. Int J Eng Sci 1970;8:643-56.

[10] Schapery RA. A theory of crack initiation and growth in viscoelastic media part I: theoretical development. Int J Fracture 1975;11:141-59.

[11] Christensen RM. Theory of viscoelasticity. New York: Dover; 1982.

[12] Knauss WG. Time dependent fracture and cohesive zones. J Eng Mater Technol 1993;115:263-7.

[13] Dugdale DS. Yielding of steel sheets containing slits. J Mech Phys Solids 1960;8:100-4.

[14] Barenblatt GI. The mathematical theory of equilibrium cracks in brittle fracture. Adv Appl Mech 1962;7:55-129.

[15] Allen DH, Searcy CR. A micromechanical model for a viscoelastic cohesive zone. Int J Fracture 2001;107:159-76.

[16] Allen DH, Searcy CR. A micromechanically based model for predicting dynamic damage evolution in ductile polymers. Mech Mater 2001;33:177-84.

[17] Costanzo F, Allen DH. A continuum mechanics approach to some problems in subcritical crack propagation. Int J Fracture 1993;63:27-57.

[18] Yoon C, Allen DH. Damage dependent constitutive behavior and energy release rate for a cohesive zone in a thermoviscoelastic solid. Int J Fracture 1999;96:56-74.
[19] Needleman A. A continuum model for void nucleation by inclusion debonding. J Appl Mech 1987;54:525-31.

[20] Tvergaard V. Micromechanical modeling of fibre debonding in a metal reinforced by short fibers. In: Proceedings of IUTAM symposium inelastic deformation of composite materials. New York: Springer; 1990. p. 99-111

[21] Sha Y, Hui CY, Ruina A, Kramer EJ. Detailed simulation of craze fibril failure at a crack tip in a glassy polymer. Acta Mater 1997;45:3555-63.

[22] Tvergaard V, Hutchinson JW. The influence of plasticity on mixed mode interface fracture toughness. J Mech Phys Solids 1993;41:1119-35.

[23] Espinosa HD, Zavattieri PD, Dwivedi SK. A finite deformation continuum/ discrete model for the description of fragmentation and damage in brittle materials. J Mech Phys Solids 1998;46:1909-42.

[24] Van der Burg MWD, Van der Giessen E. Simulation of microcrack propagation in creeping polycrystals due to diffusive grain boundary cavitation. Appl Mech Rev 1994;47:122-31.

[25] Costanzo F, Walton JR. A study of dynamic crack growth in elastic materials using a cohesive zone model. Int J Eng Sci 1997;35:1085-114.

[26] Costanzo F, Walton JR. Numerical simulations of a dynamically propagating crack with a nonlinear cohesive zone. Int J Fracture 1999;91:373-89.

[27] Chou SC, Deluca E. Dynamic response of S-2 glass reinforced plastic structural armor - a progress report. Army Research Laboratory, ARL-SR-5; 1993.

[28] Gazonas GA, Allen DH. Stress Waves and cohesive failure in a finite strip subjected to transient loading. In: Proceedings of 9th international conference mechanical behaviour of materials. Geneva, Switzerland; 2003.

[29] Hallquist JO. User's manual for DYNA2D - an explicit two-dimensional hydrodynamic finite element code with interactive rezoning. University of California, Lawrence Livermore National Laboratory, Report No. UCID-18756; 1982.

[30] Allen DH, Jones RH, Boyd JG. Micromechanical analysis of a continuous fiber metal matrix composite including the effects of matrix viscoplasticity and evolving damage. J Mech Phys Solids 1994;42(3):505-29.

[31] Ortiz M, Pandolfi A. Finite-deformation irreversible cohesive elements for three-dimensional crack-propagation analysis. Int J Numer Methods Eng 1999;44(9):1267-82.

[32] Espinosa HD, Zavattieri PD. A grain level model for the study of failure initiation and evolution in polycrystalline brittle materials. Part I: theory and numerical implementation. Mech Mater 2003;35:333-64.

[33] Souza FV, Soares JB, Allen DH, Evangelista F. Model for predicting damage evolution in heterogeneous viscoelastic asphaltic mixtures. Transport Res Rec 2004;1891:131-9.

[34] Zhou F, Molinari JF. Dynamic crack propagation with cohesive elements: a methodology to address mesh dependency. Int J Numer Methods Eng 2004;59:1-24.

[35] Kim Y, Allen DH, Little DN. Damage-induced modeling of asphalt mixtures through computational micromechanics and cohesive zone fracture. J Mater Civil Eng 2005;17(5):477-84.

[36] Kim H, Buttler WG. Micromechanical fracture modeling of hot-mix asphalt concrete based on a disk-shaped compact tension test. Electronic J Ass Asphalt Paving Technol 2005;74E.

[37] Molinari JF, Gazonas GA, Raghupathy R, Rusinek A, Zhou F. The cohesive element approach to dynamic fragmentation: the question of energy convergence. Int J Numer Methods Eng 2007;69(3):484-503.

[38] Lagoudas DC, Ma X, Xu S. Surface damage modeling of oxidized metal matrix composite laminates under axial and transverse tension. Int J Damage Mech 1998;7:209-37.

[39] Kim Y, Allen DH, Seidel GD. Damage-induced modeling of elastic-viscoelastic randomly oriented particulate composites. J Eng Mater Technol 2006;128(1):18-27.

[40] Kim Y, Allen DH, Little DN. A computational constitutive model for predicting nonlinear viscoelastic damage and fracture failure of asphalt concrete mixtures. Int J Geomech 2007;7(2):102-10.

[41] Camacho GT, Ortiz M. Computational modelling of impact damage in brittle materials. Int J Solids Struct 1996;33:2899-938.

[42] Kanninen MF, Popelar CH. Advanced fracture mechanics. New York: Oxford Engineering Science Series 15, Oxford University Press; 1985.

[43] Tvergaard V. Effect of fiber debonding in a whisker-reinforced metal. Mater Sci Eng 1990;125(2):203-13. 